\title{
Assessment of quality attributes of tomato sauce supplemented with moringa root
}

\author{
Ahmed DIN ${ }^{1}$, Rai Muhammad AMIR ${ }^{2 *}$ (D), Kashif AMEER ${ }^{2}$, Asif AHMAD², Muhammad NADEEM ${ }^{3}$, \\ Muhammad Farhan Jahangir CHUGHTAI ${ }^{4}$, Adnan KHALIQ ${ }^{4}$, SAMREEN AHSAN ${ }^{4}$, Muhammad Imran Khan ${ }^{5}$, \\ Aayesha RIAZ ${ }^{6}$, Rukhsana KAUSAR
}

\begin{abstract}
This study was conducted to evaluate the quality and mineral contents of Moringa oleifera root-based tomato sauce. Results showed that roots of $M$. oleifera are highly enriched with essential nutrients including minerals, such as iron, sodium, magnesium, calcium, potassium and zinc and vitamins specifically vitamin C. Thus, it is useful as a nutritional supplement to enhance the nutritional status of the people and communities especially the susceptible groups including children and women. The tomato sauce supplemented with moringa roots is an effective remedy of malnutrition. TSS, $\mathrm{pH}$, \% acidity, Vitamin $\mathrm{C}$ were showed highly significant differences among all the treatments and the effect of days on TSS and Vitamin C were also showed highly significant $(p<0.05)$ differences while $\mathrm{pH}$ and $\%$ acidity showed significant effects and the interactive effect of treatments and days were found highly significant on Vitamin $\mathrm{C}$ while TSS, $\mathrm{pH}$ and $\%$ acidity all were found non-significant. $\mathrm{T}_{4}$ (tomato sauce supplemented with $35 \mathrm{~g}$ ) showed improved or comparable sensory properties to those of control and mineral profile also showed increasing tendency with corresponding rise in moringa root juice.
\end{abstract}

Keywords: tomato sauce; moringa roots; physicochemical properties; sensory quality.

Practical Application: Moringa may be exploited in formulation of supplemented products.

\section{Introduction}

Moringa (Moringa oleifera Lam), belongs to the family Moringaceae, is a very familiar medicinal herb in various tropical and subtropical countries to cure many ailments (Kunyanga et al., 2013). In Pakistan, Moringa oleifera is well known as 'Sohanjna' and is grown and produced in almost every part of the country. It is used in many medicines and has major nutritional effects because of presence of various components, such as amino acids, nutrients, anti-aging, anti-inflammatory and antioxidant (Tejas et al., 2012).

Moringa has many more health benefits which are diuretic, hepatoprotective, antispasmodic and antimicrobial activity (Toma \& Deyno, 2014). The roots of this plant are used in folk medicine as anti-inflammatory agent, helpful in paralytic afflictions, and are used as cardiac/ circulatory stimulant. It is also helpful as a laxative, in treating rheumatism, inflammations, articular pains, lower back or kidney pain, constipation, abdominal tumors, hysteria, scurvy, helminitic, common cold, diarrhea, flatulence and edema (Jideani \& Diedericks, 2014).

Moringa nutrcautical potential can be exploited to develop novel products, such as tomoto sauce. Tomato ranks second as the most consumed and produced crop (Oboulbiga et al., 2017) and comprises of significant lycopene. Lycopene is not produced by human body and is normally replenished by taking from diet as powerful antioxidant. There is much probability that intake of tomatoes and products fortified with tomato are helpful in prevention of serum-lipid oxidation and lower the threat of macular degenerative diseases (Bhowmik et al., 2012; Raiola et al., 2014). A very limited data is available about tomato sauce supplementation with moringa root. To the best of our knowledge, this is first report on value-addition of tomato sauce in terms of supplementation to combat malnutrition. Furthermore, assessment of quality characteristics was carried out during storage periods of 0 to 90 days at regular intervals.

\section{Materials and Methods}

\subsection{Procurement of raw material and preparation}

The roots of M. oleifera were purchased from local market of Faisalabad. Tomatoes for the research were acquired from Ayub Agricultural Research Institute, Faisalabad. Then, a pot full of water was placed on the stove and boiled. Tomatoes were kept in boiling water for $30 \mathrm{~s}$ or till the time skins started peeling off. Then, tomatoes were kept in ice water and skins of all tomatoes were peeled off. 


\subsection{Washing of Moringa oleifera roots and tomatoes}

Collected roots and tomatoes were washed with running tap water for cleaning followed by dipping in $1 \%$ saline solution $(\mathrm{NaCl})$ for $5 \mathrm{~min}$ to for microbial decontamination. Afterward, again washing was carried out twice with distilled water.

\subsection{Preparation of Moringa oleifera roots and tomato pulps}

Moringa roots after washing, sorting and trimming goes for the preparation of pulp. For that purpose, moringa roots were crushed in the blender to make a fine paste. Peeled tomatoes were cut into pieces of one inch each. The tomatoes were heated for $25 \mathrm{~min}$ at boiling temperature in pot until they were soft enough for pulping purpose. After that pulp was processed further in fine mesh pulper (Nasir et al., 2014).

\subsection{Preparation of tomato sauce}

Sauce preparation was carried out using ingredients, such as tomato and Moringa roots according to the treatment plan. All treatment samples treatments were prepared by following the standard recipe formula given in Table 1.

\subsection{Experimental plan and storage study}

Tomato sauce was prepared by the standard recipe formula and Moringa oleifera roots in different concentrations were added to this sauce as per treatment plan given in Table 2. During storage phase, physiochemical properties of sauce and hedonic feedback of the tomato sauce was evaluated at precise intervals of $0,30,60$ and 90 days.

\subsection{Quality parameters analysis of tomato sauce}

\section{Physiochemical properties}

Moringa oleifera root juice and tomato sauce were evaluated by physicochemical tests, such as total soluble solids (TSS), $\mathrm{pH}$, $\%$ acidity, Vitamin $\mathrm{C}$ and Minerals i.e., $\mathrm{Na}, \mathrm{K}, \mathrm{Ca}, \mathrm{Mg}$, Fe and Zn.

\section{Determination of TSS}

Total soluble solids were measured as described by Vázquez-Araújo et al. (2011) using a refractometer (Model No. ABBE'S refractometer, Bellingham, BS Eclipse, UK, 45-03), and measurement was expressed as ${ }^{\circ}$ Brix at $30-35^{\circ} \mathrm{C}$.

\section{pH determination}

pH was measured by method described by Vázquez-Araújo et al. (2011) by pH meter (Model No. Jenway 3510-UK). The $\mathrm{pH}$ meter was calibrated by buffers of $\mathrm{pH}$ 7.00 and 4.00 prior to its use.

\section{Titratable acidity}

The percentage of acidity was measured by method of Association of officials of Analytical Chemists (2006).

Determination of ascorbic acid (vitamin C) in tomato sauce

Visual titration technique was used to found out the quantity of ascorbic acid along with 2, 6-dichloropheno-lindophenol dye solution in sample according to method of Association of officials of Analytical Chemists (2006) with some modifications.

\subsection{Mineral analysis of tomato sauce}

Wet digestion process was carried out at Institute of Home Sciences (IHS), University of Agriculture Faisalabad. Minerals profile was found out by atomic absorption spectrophotometer (Hitachi Polarized Zeeman AAS, Z-8200, Japan) in the pre-treated samples as per conditions defined in Association of officials of Analytical Chemists (2006).

\subsection{Sensory evaluation}

The sensory attributes, such as color, taste, flavor, sweetness and overall acceptability were evaluated by trained panelist of fresh samples as well during storage period. Sensory evaluation of prepared sauces was rated using 9-point hedonic scale system which ranges from extremely like to very dislike ( $9=$ like extremely; 1 = dislike extremely) in the sensory evaluation laboratory of the IHS, University of Agriculture, Faisalabad (Meilgaard et al., 2007).

\subsection{Statistical analysis}

All measurements were recorded in triplicate and results were expressed as mean + standard deviation (S.D.). Moreover, the data was subjected to one-way analysis of variance using Microsoft Excel (ver. 2016, Microsoft Corp. USA) and difference between the means was evaluated by student t-test at significance level of $p<0.05$ (Montgomery, 2008).

Table 1. Standard recipe formula.

\begin{tabular}{cccc}
\hline Ingredients $^{*}$ & Quantity & Ingredients & Quantity \\
\hline Onion & $0.5 \mathrm{~kg}$ & Sugar & $1 \mathrm{~kg}$ \\
Garlic & $12 \mathrm{~g}$ & Sodium benzoate & $5 \mathrm{~g}$ \\
Cloves & $5 \mathrm{~g}$ & Vinegar & $25 \mathrm{~mL}$ \\
Cinnamon & $6 \mathrm{~g}$ & Xanthan gum & $10-15 \mathrm{~g}$ \\
Red pepper & $20 \mathrm{~g}$ & Brix & $33-35$ \\
Salt & $120 \mathrm{~g}$ & Hot spices & $10 \mathrm{~g}$ \\
\hline
\end{tabular}

${ }^{\star}$ For each $5 \mathrm{~kg}$ formula 


\section{Results and Discussion}

\subsection{Physicochemical characteristics of moringa root juice and tomato juice}

Tomato sauce supplemented with moringa roots juice were analyzed for physiochemical parameters such as TSS, $\mathrm{pH}$, titratable acidity, vitamin $\mathrm{C}$ and minerals of Moringa oleifera root juice and tomato juice were determined and data is presented in Table 3.

\section{Total Soluble Solids (TSS)}

The mean values of TSS of moringa root juice and tomato juice are shown in Table 3. The TSS contents (\%) of moringa root juice and tomato juice were $2.0 \pm 0.05$ and $3.20 \pm 0.13$ respectively (Table 3 ). A comparable value of TSS of Moringa oleifera i.e. $1.43 \pm 0.02 \%$ was observed by researchers who studied the physicochemical characteristics of Moringa oleifera (Jesmin et al., 2014).

Table 2. Treatment plan.

\begin{tabular}{cc}
\hline Treatments & Moringa oleifera root $(\mathrm{g})$ \\
\hline $\mathrm{T}_{1}$ & Commercially available tomato sauce \\
$\mathrm{T}_{2}$ & 15 \\
$\mathrm{~T}_{3}$ & 25 \\
$\mathrm{~T}_{4}$ & 35 \\
$\mathrm{~T}_{5}$ & 45 \\
\hline
\end{tabular}

Table 3. Physiochemical and mineral analyses of Moringa root juice and tomato juice.

\begin{tabular}{|c|c|c|}
\hline \multicolumn{3}{|c|}{$\begin{array}{l}\text { Physiochemical } \\
\text { parameters }\end{array}$} \\
\hline Parameters & Moringa root juice & Tomato sauce \\
\hline TSS & $2.0 \pm 0.05$ & $3.20 \pm 0.13$ \\
\hline $\mathrm{pH}$ & $6.34 \pm 0.16$ & $4.62 \pm 0.05$ \\
\hline$\%$ acidity & $0.19 \pm 0.12$ & $0.77 \pm 0.11$ \\
\hline Vitamin C (mg/100 mL) & $121.21 \pm 0.14$ & $33.33 \pm 0.04$ \\
\hline \multicolumn{3}{|c|}{ Minerals analysis } \\
\hline Minerals & $\begin{array}{c}\text { Moringa root Juice } \\
(\mathrm{ppm})\end{array}$ & Tomato sauce (ppm) \\
\hline Calcium & $301.07 \pm 0.42$ & $25.12 \pm 0.20$ \\
\hline Iron & $20.04 \pm 0.04$ & $10.62 \pm 0.32$ \\
\hline Zinc & $36.50 \pm 0.02$ & $11.19 \pm 0.18$ \\
\hline Magnesium & $58.79 \pm 0.21$ & $40.33 \pm 0.26$ \\
\hline Sodium & $32.17 \pm 0.15$ & $37.11 \pm 0.10$ \\
\hline Potassium & $815 \pm 0.26$ & $212 \pm 0.05$ \\
\hline
\end{tabular}

$p H$

The means of $\mathrm{pH}$ values of moringa root juice and tomato juice have been shown in Table 4 . The $\mathrm{pH}$ values of moringa root juice and tomato juice were $6.34 \pm 0.16$ and $4.62 \pm 0.05$ respectively (Table 3 ). Whereas, similar $\mathrm{pH}$ values were observed in reported studies of both Moringa oleifera (6.50) and of tomato juice (4.59) (Igile et al., 2016).

\section{Titratable acidity}

The means of titratable acidity values of moringa root juice and tomato juice are shown in Table 3. The titratable acidity (\%) values of moringa root juice and tomato juice were $0.19 \pm 0.12$ and $0.77 \pm 0.11$ respectively (Table 3 ). Whereas, similar titratable acidity values were determined in reported studies of both Moringa oleifera i.e. $0.49 \pm 0.08 \%$ and $0.26 \pm 0.01 \%$ of tomato juice (Jesmin et al., 2014).

\section{Vitamin C}

The means of vitamin $\mathrm{C}$ contents of moringa root juice and tomato juice are shown in Table 3 . The vitamin $\mathrm{C}$ contents $(\mathrm{mg} / 100 \mathrm{~mL})$ of moringa root juice and tomato juice were 121.21 \pm 0.14 and 33.33 \pm 0.04 , respectively (Table 3 ).

\subsection{Minerals analysis}

Minerals contents were studied in moringa root juice and tomato juice by subsequent particular methods as stated before. Means of minerals analysis of moringa root juice and tomato juice such as sodium $(\mathrm{Na})$, potassium $(\mathrm{K})$, calcium $(\mathrm{Ca})$, magnesium $(\mathrm{Mg})$, iron $(\mathrm{Fe})$ and zinc $(\mathrm{Zn})$ were are shown in Table 3.

The means of sodium contents of moringa root juice and tomato juice have been shown in Table 3 . The ppm sodium contents of moringa root juice and tomato juice were $32.17 \pm 0.15$ and $37.11 \pm 0.10$ respectively. The ppm potassium contents of moringa root juice and tomato juice were $815 \pm 0.26$ and $212 \pm 0.05$ respectively. Similar potassium concentration was observed in reported studies of both moringa root juice i.e. $860.59 \pm 0.01 \mathrm{ppm}$ and $197.00 \pm 1.15$ ppm in tomato juice (Verma \& Rajni, 2014; Igile et al., 2016). The ppm calcium contents of moringa root juice and tomato juice were $301.07 \pm 0.42$ and $25.12 \pm 0.20$ respectively. The ppm magnesium contents of moringa root juice and tomato juice were $58.79 \pm 0.21$ and $40.33 \pm 0.26$ respectively. The ppm iron contents of moringa root juice and tomato juice were $20.04 \pm 0.04$ and $10.62 \pm 0.32$ respectively. The ppm zinc contents of moringa root juice and tomato juice were $36.50 \pm 0.02$ and $11.19 \pm 0.18$ respectively.

Table 4. Means for mineral composition (ppm) of tomato sauce supplemented with moringa roots.

\begin{tabular}{ccccccc}
\hline Treatment & $\mathrm{Na}$ & $\mathrm{K}$ & $\mathrm{Ca}$ & $\mathrm{Mg}$ & $\mathrm{Fe}$ & $\mathrm{Zn}$ \\
\hline $\mathbf{T}_{1}$ & $37.110 \pm 0.5 \mathrm{e}$ & $212.0 \pm 0.5 \mathrm{e}$ & $25.120 \pm 0.5 \mathrm{e}$ & $40.330 \pm 0.5 \mathrm{e}$ & $10.620 \pm 0.5 \mathrm{~d}$ & $11.190 \pm 0.5 \mathrm{e}$ \\
$\mathbf{T}_{2}$ & $69.280 \pm 0.5 \mathrm{~d}$ & $1027.0 \pm 0.5 \mathrm{~d}$ & $326.19 \pm 0.5 \mathrm{~d}$ & $99.120 \pm 0.5 \mathrm{~d}$ & $30.660 \pm 0.5 \mathrm{c}$ & $47.690 \pm 0.5 \mathrm{~d}$ \\
$\mathbf{T}_{3}$ & $71.350 \pm 0.5 \mathrm{c}$ & $1057.8 \pm 0.5 \mathrm{c}$ & $335.97 \pm 0.5 \mathrm{c}$ & $102.09 \pm 0.5 \mathrm{c}$ & $31.570 \pm 0.5 \mathrm{c}$ & $49.120 \pm 0.5 \mathrm{c}$ \\
$\mathbf{T}_{4}$ & $74.920 \pm 0.5 \mathrm{~b}$ & $1110.7 \pm 0.5 \mathrm{~b}$ & $352.77 \pm 0.5 \mathrm{~b}$ & $107.19 \pm 0.5 \mathrm{~b}$ & $33.150 \pm 0.5 \mathrm{~b}$ & $51.570 \pm 0.5 \mathrm{~b}$ \\
$\mathbf{T}_{5}$ & $80.170 \pm 0.5 \mathrm{a}$ & $1188.5 \pm 0.5 \mathrm{a}$ & $377.47 \pm 0.5 \mathrm{a}$ & $114.79 \pm 0.5 \mathrm{a}$ & $35.480 \pm 0.5 \mathrm{a}$ & $55.190 \pm 0.5 \mathrm{a}$ \\
\hline
\end{tabular}




\subsection{Analysis of tomato sauce supplemented with moringa roots}

Tomato sauce samples were analyzed for physiochemical parameters and mineral profile by methods as stated before.

\section{Physiochemical properties}

Mean values of physiochemical parameters of tomato sauce supplemented with moringa roots, such as TSS, $\mathrm{pH}, \%$ acidity, vitamin $\mathrm{C}$ were shown in Figure 1. TSS, pH, \% acidity, Vitamin $\mathrm{C}$ showed highly significant differences among all treatments and effect of days on TSS and Vitamin $\mathrm{C}$ were also showed highly significant differences while $\mathrm{pH}$ and \% acidity showed significant effects and the interactive effect of treatments and days were found highly significant on Vitamin C while TSS, pH and $\%$ acidity all were found non-significant (Figure 1).

Total soluble solids

The results showed that treatments have highly significant effect $(p<0.05)$ on TSS as shown in Figure 1A. The mean value of TSS of treatments showed that $\mathrm{T}_{5}$ (tomato sauce supplemented with $45 \mathrm{~g}$ moringa roots) had the highest value 28.50 , followed by $\mathrm{T}_{3}$ (tomato sauce supplemented with $25 \mathrm{~g}$ moringa roots) i.e. 27.30. While the treatments $T_{4}$ and $T_{1}$ in which tomato sauce supplemented with $35 \mathrm{~g}$ moringa roots and commercially available tomato sauce respectively showed approximately similar mean values i.e. 26.30 and 26.20 . The least value i.e. 24.90 was observed in $\mathrm{T}_{2}$ in which tomato sauce supplemented with $15 \mathrm{~g}$ of moringa roots. The results of the study revealed that treatment $\mathrm{T}_{5}$ showed the best results among all the treatments. The total soluble solid contents of $\mathrm{T}_{5}$ were highest among all the treatments as shown in Figure 1A. The results of storage study were highly significant and it was evident that TSS significantly decrease after three months of storage. The TSS content at $0,30,60$ and 90 days were found to be 34.14, 29.14, 23.64 and 19.64, respectively. The results indicated that treatment $\mathrm{T}_{5}$ in which tomato sauce was supplemented with $45 \mathrm{~g}$ moringa roots showed the best results, the change of TSS was minimum over the course of storage study.

\section{$\mathrm{pH}$}

The results showed that treatments have highly significant effect on $\mathrm{pH}$ as shown in Figure 1B. The mean value of $\mathrm{pH}$ of treatments showed that $\mathrm{T}_{1}$ (commercially available tomato sauce) had the highest value 4.55 , followed by $\mathrm{T}_{5}$ (tomato sauce supplemented with $45 \mathrm{~g}$ moringa roots) i.e. 2.67. While the treatment $\mathrm{T}_{2}$ in which tomato sauce supplemented with $15 \mathrm{~g}$ moringa roots showed mean value i.e. 2.65. The mean values of tomato sauce supplemented with $35 \mathrm{~g}(\mathrm{~T} 4)$ and $25 \mathrm{~g}\left(\mathrm{~T}_{3}\right)$ moringa roots showed the lowest value i.e. 2.54 and 2.51 respectively. The results of he study revealed that treatment $\mathrm{T}_{5}$ showed the best results among all the treatments. The $\mathrm{pH}$ contents of $\mathrm{T}_{5}$ were closest to $\mathrm{T}_{1}$ among all the treatments as shown in Figure 1B. The results of storage study were significant $(p<0.05)$ and it was shown that $\mathrm{pH}$ significantly decreased after three months of
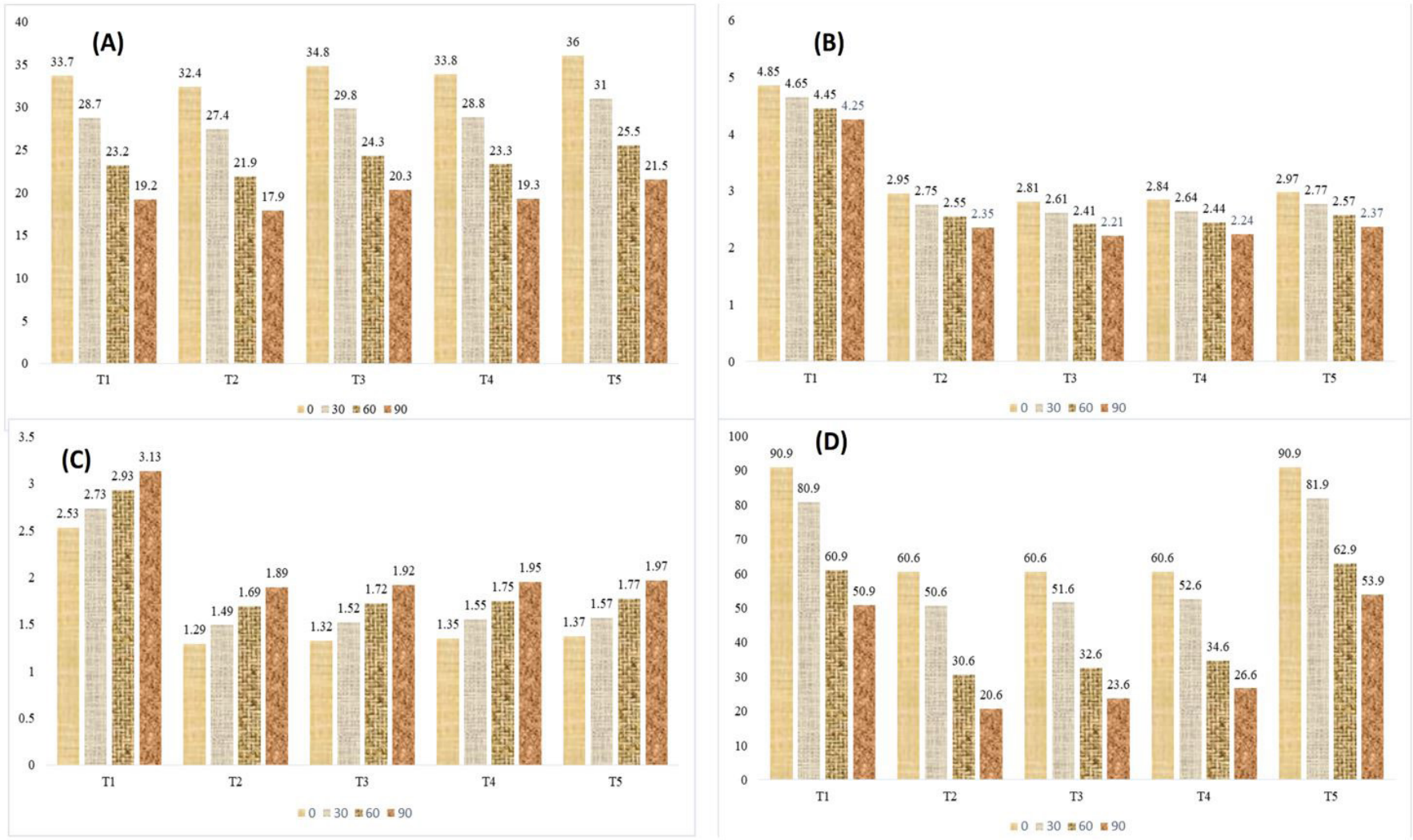

Figure 1. Effects of various treatments and storage intervals on physiochemical parameters of tomato sauce supplemented with moringa roots: TSS (A), pH (B), \% acidity (C) and vitamin C (D). 
storage. The results indicated that treatment $\mathrm{T}_{5}$ in which tomato sauce was supplemented with $45 \mathrm{~g}$ moringa roots showed the best results, the change of $\mathrm{pH}$ was minimum among all treatments and nearest to $T_{1}$ over the course of storage study.

\section{Titratable acidity}

The results showed that treatments have highly significant effect on \% acidity as shown in Figure 1C. The mean value of $\%$ acidity of treatments showed that $\mathrm{T}_{1}$ (commercially available tomato sauce) had the highest value 2.83 , followed by $\mathrm{T}_{5}$ (tomato sauce supplemented with $45 \mathrm{~g}$ moringa roots) i.e. 1.67. While the treatments in which tomato sauce supplemented with $35 \mathrm{~g}$ (T4) and $25 \mathrm{~g}\left(\mathrm{~T}_{3}\right)$ moringa roots showed the mean values i.e. 1.65 and 1.62 respectively. The mean value of $\mathrm{T}_{2}$ in which tomato sauce supplemented with $15 \mathrm{~g}$ moringa roots showed lowest value i.e. 1.59 . The results of the study revealed that treatment $T_{5}$ showed the best results among all the treatments. The $\%$ acidity contents of $\mathrm{T}_{5}$ were closest to $\mathrm{T}_{1}$ among all the treatments as shown in Figure 1C. The results of storage study were significant and it showed that $\%$ acidity significantly increase after three months of storage. The $\%$ acidity at $0,30,60$ and 90 days were found to be $1.57,1.77,1.97$ and 2.17 respectively. The interactive effect of $\mathrm{T}_{2}$ at 90 th day showed approximately $46.51 \%$ increase in the $\%$ acidity when compared to 0 day followed by the treatment T3 (45.45\%). The results indicated that treatment $\mathrm{T}_{5}$ in which tomato sauce was supplemented with $45 \mathrm{~g}$ moringa roots showed the best results, the change of $\%$ acidity was minimum among all treatments.

\section{Vitamin C}

The results showed that treatments have highly significant effect on vitamin $C$ as shown in Figure 1D. The mean value of vitamin $\mathrm{C}$ of treatments showed that $\mathrm{T}_{5}$ (tomato sauce supplemented with $45 \mathrm{~g}$ moringa roots) had the highest value (72.40), followed by $\mathrm{T}_{1}$ (commercially available tomato sauce) i.e. 70.90 . While the treatments $\mathrm{T}_{4}$ and $\mathrm{T}_{3}$ in which tomato sauce supplemented with $35 \mathrm{~g}$ and $25 \mathrm{~g}$ of moringa roots respectively showed mean values i.e. 43.60 and 42.10 . The least value i.e. 40.60 was observed in T2 in which tomato sauce supplemented with $15 \mathrm{~g}$ of moringa roots. The results of the study revealed that treatment $\mathrm{T}_{5}$ showed the best results among all the treatments Figure 1D. The results of storage study were highly significant $(p<0.05)$ and it was evident that vitamin $\mathrm{C}$ significantly decreased after three months of storage. When we study the effect of storage on the treatments, the results were observed to be highly significant $(p<0.05)$ at $0,30,60$ and 90 days. The results indicated that treatment $T_{5}$ in which tomato sauce was supplemented with $45 \mathrm{~g}$ moringa roots showed the best results, the change of vitamin $\mathrm{C}$ was minimum over the course of storage study.

\section{Minerals analysis}

Sodium

The results showed that treatments have highly significant effect on sodium as shown in Table 4 . The mean value of sodium treatments showed that $\mathrm{T}_{5}$ (tomato sauce supplemented with $45 \mathrm{~g}$ moringa roots) had the highest value $80.170 \mathrm{ppm}$, followed by $\mathrm{T}_{4}$ (tomato sauce supplemented with $35 \mathrm{~g}$ moringa roots) i.e. $74.920 \mathrm{ppm}$. While the treatments $\mathrm{T}_{3}$ and $\mathrm{T}_{2}$ in which tomato sauce supplemented with $25 \mathrm{~g}$ and $15 \mathrm{~g}$ moringa roots showed mean values of $71.350 \mathrm{ppm}$ and $69.280 \mathrm{ppm}$, respectively. The results showed that as the percentage of supplementation of Moringa roots was increased in tomato sauce, the concentration of sodium increased gradually.

\section{Potassium}

The mean value of potassium treatments showed that $\mathrm{T}_{5}$ (tomato sauce supplemented with $45 \mathrm{~g}$ moringa roots) had the highest value $1188.5 \mathrm{ppm}$, followed by $\mathrm{T}_{4}$ (tomato sauce supplemented with $35 \mathrm{~g}$ moringa roots) i.e. $1110.7 \mathrm{ppm}$ (Table 4). While the treatments $\mathrm{T}_{3}$ and $\mathrm{T}_{2}$ in which tomato sauce supplemented with $25 \mathrm{~g}$ and $15 \mathrm{~g}$ moringa roots respectively showed approximately similar mean values i.e. $1057.8 \mathrm{ppm}$ and $1027.0 \mathrm{ppm}$. The table indicated that commercially available tomato sauce $\left(\mathrm{T}_{1}\right)$ have least value of mineral potassium while highest value was observed in $\mathrm{T}_{5}$ in which the tomato sauce was supplemented with $45 \mathrm{~g}$ of moringa roots as shown in Table 4.

\section{Calcium}

The mean value of calcium treatments showed that $\mathrm{T}_{5}$ (tomato sauce supplemented with $45 \mathrm{~g}$ moringa roots) had the highest value $377.47 \mathrm{ppm}$, followed by T4 (tomato sauce supplemented with $35 \mathrm{~g}$ moringa roots) i.e. $352.77 \mathrm{ppm}$. While the treatments $\mathrm{T} 3$ and T2 in which tomato sauce supplemented with $25 \mathrm{~g}$ and $15 \mathrm{~g}$ moringa roots showed mean values of $335.97 \mathrm{ppm}$ and $326.19 \mathrm{ppm}$, respectively. The least value $(25.120 \mathrm{ppm})$ was observed in $\mathrm{T}_{1}$ (commercially available tomato sauce).

\section{Magnesium}

The mean value of magnesium treatments showed that T5 (tomato sauce supplemented with $45 \mathrm{~g}$ moringa roots) had the highest value $114.79 \mathrm{ppm}$, followed by $\mathrm{T}_{4}$ (tomato sauce supplemented with $35 \mathrm{~g}$ moringa roots) i.e. $107.19 \mathrm{ppm}$. While the treatments $\mathrm{T}_{3}$ and $\mathrm{T}_{2}$ in which tomato sauce supplemented with $25 \mathrm{~g}$ and $15 \mathrm{~g}$ moringa roots showed mean values of $102.09 \mathrm{ppm}$ and $99.120 \mathrm{ppm}$, respectively. The least value of $40.330 \mathrm{ppm}$ was observed in $\mathrm{T}_{1}$ (commercially available tomato sauce).

Iron

The mean value of iron treatments showed that $\mathrm{T}_{5}$ (tomato sauce supplemented with $45 \mathrm{~g}$ moringa roots) had the highest value $35.480 \mathrm{ppm}$, followed by $\mathrm{T}_{4}$ (tomato sauce supplemented with $35 \mathrm{~g}$ moringa roots) i.e. $33.150 \mathrm{ppm}$. The least value of $10.620 \mathrm{ppm}$ was observed in $\mathrm{T}_{1}$ (commercially available tomato sauce). The results showed that the quantity of moringa roots in tomato sauce showed the linear relationship with the concentration of iron in gradual fashion.

\section{Zinc}

The mean value of zinc treatments showed that $\mathrm{T}_{5}$ (tomato sauce supplemented with $45 \mathrm{~g}$ moringa roots) had the highest value $\left(55.190 \mathrm{ppm}\right.$ ), followed by $\mathrm{T}_{4}$ (tomato sauce supplemented 
with $35 \mathrm{~g}$ moringa roots) i.e. $51.570 \mathrm{ppm}$. While the treatments $\mathrm{T}_{3}$ and $\mathrm{T}_{2}$ in which tomato sauce supplemented with $25 \mathrm{~g}$ and $15 \mathrm{~g}$ moringa roots showed mean values of $49.120 \mathrm{ppm}$ and $47.690 \mathrm{ppm}$, respectively. The least value of $11.190 \mathrm{ppm}$ was observed in $\mathrm{T}_{1}$ (commercially available tomato sauce).

\section{Sensory attributes of tomato sauce}

The mean squares of color, taste, flavor, sweetness and overall acceptability showed significant differences among all the treatments while the effect of days and the interactive effect of treatments and days were found to be non-significant (Figure 2A-E). The brief description of each attribute is given below:

\section{Color}

The results showed that treatments have significant effect on color as shown in Figure 2A. The mean value of color treatments showed that $\mathrm{T}_{1}$ (commercially available tomato sauce) and $\mathrm{T}_{4}$ (tomato sauce supplemented with $35 \mathrm{~g}$ moringa roots) had the highest value 7.77 and 7.70 respectively, followed by $\mathrm{T}_{5}$ (7.24) in which tomato sauce supplemented with $45 \mathrm{~g}$ moringa roots. The mean values of tomato sauce supplemented with $15 \mathrm{~g}\left(\mathrm{~T}_{2}\right)$ and $25 \mathrm{~g}\left(\mathrm{~T}_{3}\right)$ moringa roots showed the lowest value of 7.197 and 7.195, respectively. The results of the study revealed that treatment $\mathrm{T} 4$ showed the most appealing color property among all the treatments Figure 2A. The storage had showed no effect on the color of the tomato sauce. The color values at $0,30,60$ and 90 days were found to be $7.52,7.46,7.37$ and 7.33 respectively. The interactive effect of $\mathrm{T}_{1}$ at 90 th day showed approximately $4.27 \%$ decrease in color scores when compared to 0 day followed by the treatment $\mathrm{T}_{5}(2.4 \%)$. The results indicated that all treatments have approximately similar effects over the course of storage study.

Taste

The results showed that treatments have highly significant effect on taste as shown in Figure 2B. The taste of treatments $\mathrm{T}_{4}$ and $\mathrm{T}_{1}$ in which tomato sauce supplemented with $35 \mathrm{~g}$ moringa roots and commercially available tomato sauce respectively showed the highest and approximately similar mean values i.e. 7.22 and 7.21 , followed by $\mathrm{T}_{5}$ (7.17) in which tomato was supplemented with $45 \mathrm{~g}$ moringa roots. The mean values of tomato sauce supplemented with $25 \mathrm{~g}\left(\mathrm{~T}_{3}\right)$ and $15 \mathrm{~g}\left(\mathrm{~T}_{2}\right)$ moringa roots showed the lowest value i.e. 6.24 and 6.105 respectively. The results of the study revealed that treatment $\mathrm{T}_{4}$ showed the best results among all the treatments. The taste value of $\mathrm{T}_{4}$ was closest to $\mathrm{T}_{1}$ among all the treatments as shown in Figure $2 \mathrm{~B}$. The results of storage study were non-significant.

\section{Flavor}

The results showed that treatments have highly significant effect on flavor as shown in Figure 2B. The flavor of treatments $\mathrm{T}_{1}$ and $\mathrm{T}_{4}$ in which commercially available tomato sauce and
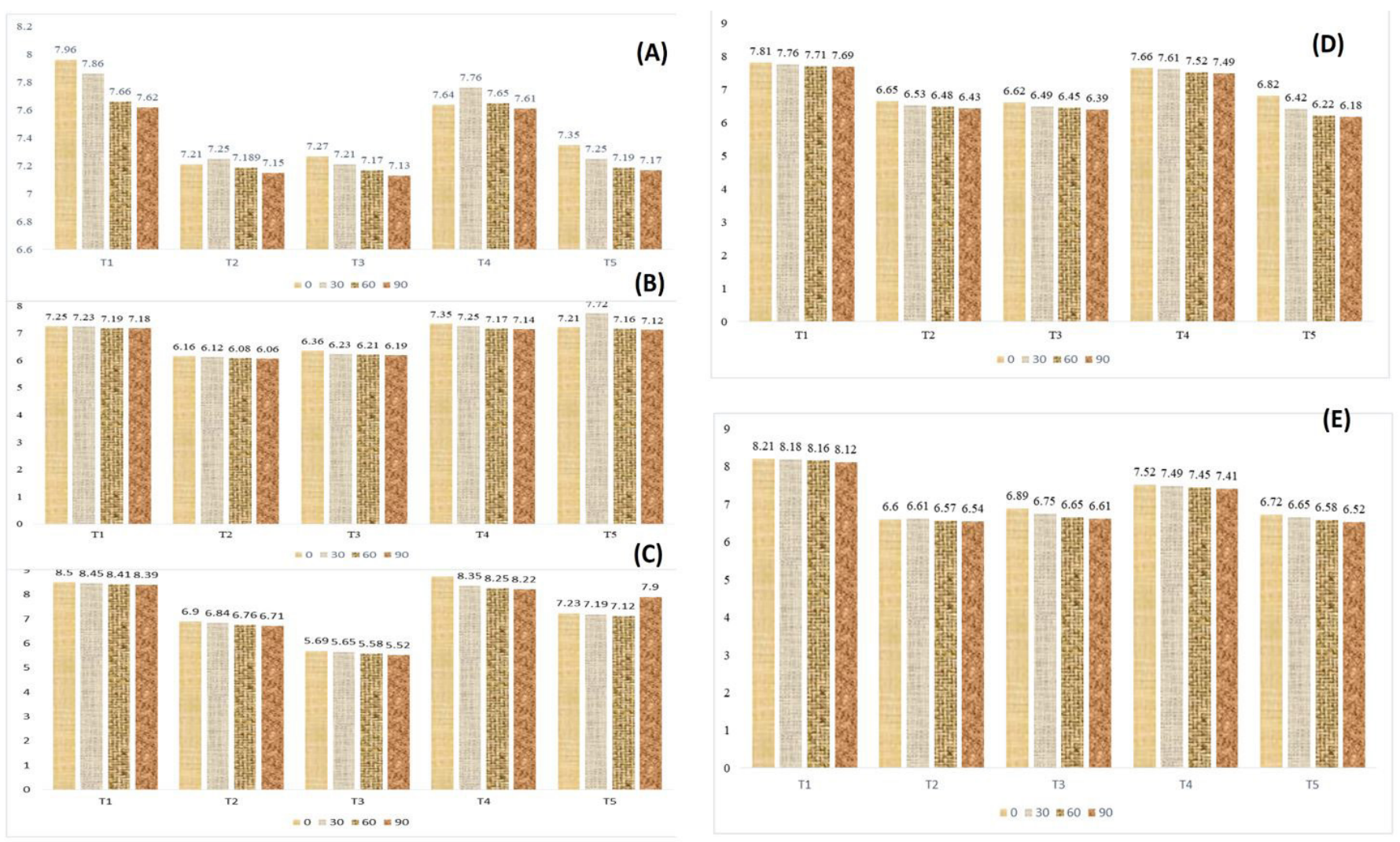

Figure 2. Effects of various treatments and storage intervals on sensory characteristics of tomato sauce supplemented with moringa roots: Color (A), Taste (B), Flavor (C) Sweetness and (D) and Overall acceptability (E). 
tomato sauce supplemented with $35 \mathrm{~g}$ moringa roots respectively showed the highest and approximately similar mean values i.e. 8.437 and 8.392 , followed by $\mathrm{T}_{5}(7.360)$ in which tomato sauce supplemented with $45 \mathrm{~g}$ moringa roots. The flavor value of $\mathrm{T}_{4}$ was closest to $\mathrm{T}_{1}$ among all the treatments as shown in Figure $2 \mathrm{C}$. The results of storage study were non-significant.

\section{Sweetness}

The result showed that treatments have highly significant effect on sweetness as shown in Figure 2D. The sweetness of treatments $\mathrm{T}_{1}$ and $\mathrm{T}_{4}$ in which commercially available tomato sauce and tomato sauce supplemented with $35 \mathrm{~g}$ moringa roots respectively showed the highest and approximately similar mean values i.e. 7.742 and 7.570 , followed by $\mathrm{T}_{2}(6.522)$ in which tomato sauce supplemented with $15 \mathrm{~g}$ moringa roots. The mean values of tomato sauce supplemented with $25 \mathrm{~g}\left(\mathrm{~T}_{3}\right)$ and $45 \mathrm{~g}(\mathrm{~T})$ moringa roots showed the lowest and approximately similar value i.e. 6.487 and 6.410 respectively. The results of the study revealed that treatment $\mathrm{T}_{4}$ showed the best results among all the treatments. The sweetness value of $\mathrm{T}_{4}$ was closest to $\mathrm{T}_{1}$ among all the treatments. The results of storage study were non-significant i.e. the storage had showed no effect on the sweetness of the tomato sauce.

\section{Overall acceptability}

The mean table showed that treatments have highly significant effect on overall acceptability as shown in Figure 2E. The mean value of overall acceptability of treatments showed that $\mathrm{T}_{1}$ (commercially available tomato sauce) had the highest value 8.16 , followed by $\mathrm{T}_{4}$ (tomato sauce supplemented with $35 \mathrm{~g}$ of moringa roots) i.e. 7.46. While the treatments $\mathrm{T}_{3}$ and $\mathrm{T}_{5}$ in which tomato sauce supplemented with $25 \mathrm{~g}$ and $45 \mathrm{~g}$ of moringa roots showed mean values of 6.72 and 6.61 , respectively. The least value i.e. 6.59 was observed in $\mathrm{T}_{2}$ in which tomato sauce supplemented with $15 \mathrm{~g}$ of moringa roots.

\section{Conclusion}

This study was conducted to evaluate the quality and mineral contents of Moringa oleifera roots based tomato sauce. Moringa oleifera roots were used to identify their nutritional properties. The tomato sauce supplemented with moringa roots is an effective remedy of malnutrition. To put in a nutshell, Moringa oleifera roots had an amazing nutritional profile with several medicinal and therapeutic effects to overcome malnutrition. The education programs of nutrition in community should aware the people about fortification and different tactics to preserve Moringa roots and their daily use in foods. Kitchen gardening programs should suggest the suitable methods for propagating and using moringa roots for cuisine purposes.

\section{References}

Association of officials of Analytical Chemists - AOAC. (2006). Official Methods of Analysis of Association of Officials of Analytical Chemists (18th ed.). Arlington: AOAC Press. https://doi.org/10.1016/0003-2670(91)87088-o.
Bhowmik, D., Kumar, K. S., Paswan, S., \& Srivastava, S. (2012). Tomato-a natural medicine and its health benefits. Journal of Pharmacognosy and Phytochemistry, 1(1), 33-43.

Igile, G. O., Ekpe, O. O., Essien, N. M., Bassey, S. C., \& Agiang, M. A. (2016). Quality characteristics of tomato juice produced and preserved with and without its seeds. Dannish Journal of Food Science and Technology, 2, 1-9.

Jesmin, A., Kabir, M. Y., Dash, P. K., \& Mannan, M. A. (2014). Physico-chemical characterization of drumstick (Moringa oleifera L.) germplasm available in south western region of Bangladesh. Journal of Biodiversity and Environmental Sciences, 5(4), 287300. [JBES]

Jideani, V. A., \& Diedericks, C. F. (2014). Nutritional, therapeutic, and prophylactic properties of Vigna subterranea and Moringa oleifera. In O. Oguntibeju, Antioxidant-Antidiabetic Agents and Human Health. (Chapter 7, pp. 241-290). Bellville, South Africa: Intech. https://doi.org/10.5772/57338.

Kunyanga, C. N., Imungi, J. K., \& Vellingiri, V. (2013). Nutritional evaluation of indigenous foods with potential food-based solution to alleviate hunger and malnutrition in Kenya. Journal of Applied Biosciences, 67(0), 5277-5288. http://dx.doi.org/10.4314/jab.v67i0.95049.

Meilgaard, M. C., Civille, G. C., \& Carr, B. T. (2007). Sensory evaluation techniques (4th ed.). Boca Raton: CRC Press. https://doi.org/10.1201/ b19493.

Montgomery, D. C. (2008). Design and analysis of experiments (17th ed., pp. 162-264). Haboken: John Wiley and Sons. Inc. https://doi. org/10.2307/1271458.

Nasir, M. U., Hussain, S., Qureshi, T. M., Nadeem, M., \& Din, A. (2014). Characterization and storage stability of tomato sauce supplemented with date pulp. International Journal of Applied Agricultural Sciences, $6,57-65$

Oboulbiga, E. B., Parkouda, C., Sawadogo-Lingani, H., Compaore, E. W. R., Sakira, A. K., \& Traore, A. S. (2017). Nutritional composition, physical characteristics and sanitary quality of the tomato variety Mongol F1 from Burkina Faso. Food and Nutrition Sciences, 8(04), 444-455. http://dx.doi.org/10.4236/fns.2017.84030.

Raiola, A., Rigano, M. M., Calafiore, R., Frusciante, L., \& Barone, A. (2014). Enhancing the health-promoting effects of tomato fruit for biofortified food. Mediators of Inflammation, 2014, 1-16. http:// dx.doi.org/10.1155/2014/139873. PMid:24744504.

Tejas, G. H., Umang, J. H., Payal, B. N., Tusharbinu, D. R., \& Pravin, T. R. (2012). A panoramic view on pharmacognostic, pharmacological, nutritional, therapeutic and prophylactic values of Moringa olifera Lam. International Research Journal of Pharmacy, 3, 1-7.

Toma, A., \& Deyno, S. (2014). Phytochemistry and pharmacological activities of Moringa oleifera. International Journal of Pharmcognosy, 1, 222-231. http://dx.doi.org/10.13040/ IJPSR.0975-8232.1(4).222-31.

Vázquez-Araújo, L., Chambers, V. E. 4th, Adhikari, K., \& CarbonellBarrachina, A. A. (2011). Physico-chemical and sensory properties of pomegranate juices with pomegranate albedo and carpellar membranes homogenate. Lebensmittel-Wissenschaft + Technologie, 44(10), 2119-2125. http://dx.doi.org/10.1016/j. lwt.2011.07.014.

Verma, K. S., \& Rajni, N. (2014). Nutritional assessment of different parts of Moringa oleifera Lamm collected from central India. Journal of Natural Product and Plant Resources, 4(1), 81-86. 